\title{
PENYELESAIAN TERHADAP KASUS PEMBUNUHAN DENGAN MENGGUNAKAN HUKUM ADAT DAYAK UUD DANUM \\ DI KABUPATEN SINTANG
}

\author{
Kartika Agus Salim \\ Fakultas Hukum Universitas Kapuas Sintang \\ Jalan Oevang Oeray 92 Sintang \\ Email : agussalimkartika401@gmail.com
}

\begin{abstract}
Abstrac
Dayak tribe Uud Danum is the majority population that inhabits two districts in Sintang District namely: Serawai and Ambalau Subdistricts. Although there are residents or other tribes who are migrants but few in the two subdistricts. The Dayak Uud Danum people who are the object of this research still hold firmly to the values or norms abandoned by their ancestors (their ancestors). Values or norms abandoned by them are perceived as an adat that continues to evolve following changes in people's lives. Keywords: Dayak tribe Uud Danum. Settlement, Murder.
\end{abstract}

\begin{abstract}
Abstrak
Suku Dayak Uud Danum merupakan penduduk mayoritas yang mendiami dua Kecamatan di Kabupaten Sintang yaitu : Kecamatan Serawai dan Ambalau. Walaupun terdapat penduduk atau suku lain yang merupakan penduduk pendatang namun
\end{abstract}

jumlahnya sedikit di dua Kecamatan tersebut. Masyarakat Dayak Uud Danum yang menjadi objek penelitian ini masih memegang teguh pada nilai - nilai atau norma - norma yang ditinggalkan oleh leluhurnya (nenek moyang mereka). Nilai - nilai atau norma - norma yang ditinggalkan oleh mereka dianggap sebagai adat yang terus berkembang mengikuti perubahan dalam kehidupan masyarakat.

Kata Kunci : Suku Dayak Uud Danum. Penyelesaian, Pembunuhan.

\section{Latar Belakang}

Perbuatan menghilangkan nyawa orang lain (munuk) dengan tidak sengaja tidak hanya merugikan ahli waris korban dan masyarakat sekitar daerah hukumnya, tetapi juga merupakan pelanggaran terhadap hukum adat yang berdampak pada keselamatan dan keseimbangan masyarakat secara lahir dan batin. Karena ada perbuatan menghilangkan nyawa orang lain (munuk) dengan tidak sengaja dapat menimbulkan suatu akibat hukum sebagai reaksi, koreksi dan perilaku 
yang mengarah kepada delik adat yang berat sehingga walaupun menurut Kitab Undang

- Undang Hukum Pidana (KUHP) si pelaku harus mendapat hukuman sesuai dengan pasal 359 KUHP dan Undang - undang No.14/70 pasal 23 dan 27, pihak keluarga/waris harus melakukan adat dengan cara membayar sanksi adat Pati Nyawa yang keberadaannya terus berkembang sesuai dengan keperluan dan rasa keadilan masyarakat adat. Menurut alam pemikiran masyarakat Dayak Uud Danum hal terpenting yang harus dijaga dan dipelihara dalam kehidupannya adalah keseimbangan, kerukunan, dan keserasian antara dunia lahir dan dunia gaib, antara golongan manusia secara keseluruhan dan orang - perorangan dan antara persekutuan masyarakat adat itu sendiri. Dalam asas Hukum Pidana yang berbunyi bahwa : "Perdamaian tidak menghapuskan proses pemiidanaan"12.

Azas tersebut memberikan kita pemahaman akan bagaimana seyogianya perjalanan suatu kasus dalam mendapatkan kekuatan hukum tetap sehingga semua pihak merasa puas sehingga dalam proses peradilan tidak terhenti begitu saja seperti yang disampaikan oleh P.A.F.Lamintang dalam hal penghentian penyidikan :

12 Moeljatno,S.H.Asas - Asas Hukum Pidana, Rineka Cipta, Cetakan ke-7, Jakarta, 2002, halaman 135 .
1. bahwa sebelum melakukan penyidikan terhadap seseorang penyidik harus benar - benar yakin bahwa orang tersebut telah melakukan tindak pidana, berdasarkan bukti - bukti pendahuluan yang telah berhasil dikumpulkan oleh penyidik.

2. bahwa penyidik harus yakin, yaitu apabila ia sekali telah memulai dengan penyidikannya, tersangka secara pasti akan dapat diajukan ke pengadilan untuk diadili.

3. bahwa penyidik harus yakin terlebih dahulu bahwa bukti - bukti atau saksi yang dapat dipergunakan untuk membuktikan kesalahan tersangka secara pasti akan dapat diperoleh"13.

\section{Pembahasan}

Menurut Ketua Dewan Adat Dayak Kabupaten Sintang masyarakat di dua Kecamatan Serawai dan Ambalau dalam yang berasal dari Suku Dayak Uud Danum lebih memilih penyelesaian kasus pembunuhan menggunakan hukum adat karena lebih cepat, tidak rumit, singkat dan biaya murah. Menurut 5 (lima) orang penyidik Kepolisian Resort Sintang terkait penyelesaian Kasus Pembunuhan yang diselesaiakan oleh melalui Hukum Adat cukup banyak seperti pada dibawah tabel 4.1 sebagai berikut :

13 P.A.FLamintang , Kitab Undang Undang Hukum Acara Pidana dengasn pembahasan secar Yuridis menurut Yurisprudensi dan Ilmu Pengetahuan Hukum Pidana, Sinar Baru, Bandung, 1984, halamn 76 
Tabel 4.1. Jumlah Kasus Pembunuhan Yang terjadi dari Tahun 2000 - 2010 pada Masyarakat Dayak Uud Danum di Kabupaten Sintang

\begin{tabular}{|c|c|c|c|c|c|}
\hline No. & Nama Kasus & Kasus & Tahun & $\begin{array}{l}\text { Tempat } \\
\text { Kejadian }\end{array}$ & $\begin{array}{c}\text { Penyelesaian } \\
\text { Kasus }\end{array}$ \\
\hline 1. & $\begin{array}{l}\text { Kecelakaan } \\
\text { saat kerja di } \\
\text { Ladang }\end{array}$ & 1 & 2000 & $\begin{array}{l}\text { Begori, } \\
\text { Kecamatan } \\
\text { Serawai, } \\
\text { Kabupaten } \\
\text { Sintang }\end{array}$ & $\begin{array}{l}\text { Menggunakan } \\
\text { Hukum Adat } \\
\text { Dayak Uud } \\
\text { Danum }\end{array}$ \\
\hline 2. & $\begin{array}{l}\text { Tabrakan } \\
\text { Speed Boat } \\
\text { di Sungai } \\
\text { Melawi } 1\end{array}$ & 1 & 2001 & \begin{tabular}{|l} 
Nanga \\
Kemangai, \\
Kecamatan \\
Ambalau, \\
Kabupaten \\
Sintang \\
\end{tabular} & $\begin{array}{l}\text { Menggunakan } \\
\text { Dayak Uud } \\
\text { Danum }\end{array}$ \\
\hline 3. & $\begin{array}{l}\text { Tabrakan } \\
\text { Speed Boat } \\
\text { di Sungai } \\
\text { Melawi }\end{array}$ & 1 & 2010 & \begin{tabular}{|l} 
Nanga \\
Kemangai, \\
Kecamatan \\
Ambalau, \\
Kabupaten \\
Sintang
\end{tabular} & $\begin{array}{l}\text { Menggunakan } \\
\text { Hukum Adat } \\
\text { Dayak Uud } \\
\text { Danum }\end{array}$ \\
\hline
\end{tabular}

Sumber : data hasil penelitian di lapangan yang diolah, Tahun 2011.

Keputusan Musyawarah fungsionaris adat Kecamatan Serawai dan Ambalau telah merumuskan ketentuan adat pati nyawa yang berlaku untuk 46 Desa yang kemudian disahkan dengan keputusan Dewan Adat Dayak Kabupaten Sintang. Keputusan musyawarah Fungsionaris Adat Dayak Uud Danum sebelum direvisi yaitu sebagai berikut berkaitan dengan ketentuan hukum Adat Patinyawa. Ketaatan masyarakat Dayak Uud Danum terhadap hukum Adatnya ini dikarenakan setiap perbuatan yang dilanggar oleh masyarakat adat terhadap ketentuan adat akan diberi sanksi adat setempat. Pemberian sanksi terhadap pelaku pelanggaran peraturan adat oleh pengurus adat bermaksud untuk memulihkan keseimbangan kehidupan masyarakat sehari - hari yang sebelumnya berjalan harmonis. Keharmonisan kehidupan masyarakat Adat di suatu kampung dijungjung tinggi ini berdampak terhadap hubungan antara sesama dan alam disekitarnya.

\section{Menurut Temenggung Dewan}

Adat Dayak Kabupaten Sintang bahwa dalam peradilan Adata Dayak Uud Danum untuk menyelesaikan kasus pembunuhan dilaksanakan dengan tiga bentuk yaitu : 1). Pemenuhan Tuntutan Sanksi Adat Pati Nyawa, 2). Membayar/melaksanakan adat pati nyawa, 30. Menyerahkan barang - barang antik. Semua keperluan yang diperlukan tersebut digunakan untk pelaksanaan tindakan dan upaya - upaya pemulihan sesuai dengan kebutuhan penyelesaian perkara dan merupakan kewajiban pihak pelaku untuk memenuhinya. Maka secepatnya itu juga fungsionaris adat melaksanakan tindakan dan upaya - upaya yang diperlukan apabila terdapat situasi pelaku tidak mau mengakui perbuatannya yang menghilangkan nyawa orang lain seperti yang dituduhkan kepadanya.

Selain itu masyarakat mendesak secepatnya mendapatkan pemulihan keseimbangan dalam kehidupan mereka sehari - hari, pelaku yang pada kesempatan itu tidak memiliki saksi yang memberikan keterangan sehingga meringankan si pelaku maka fungsionaris adat harus melakukan 
tindakan penyelesaian. Dengan demikian kesucian alam, roh para leluhur dan roh sakti lainnya yang berada di alam ghaib tidak terganggu. Masyarakat pun terhindar dari bencana alam dan mala petaka yang diopercayai akan menimpa mereka apabila noda akibat perbuatan pelaku tersebut tidak dibersihkan. Dengan terlaksananya tuntutan/ sanksi adat untuk menyelesaikan perkara adat patinyawa ini, maka masyarakat pun merasa ada kedamaian, ketertiban, dan keharmonisan dilingkungan mereka dengan sikap masyarakat tetap menerima tuntutan/ sanksi adat yang dipatuhi oleh pelaku untuk menjaga keseimbangan masyarakat adat. Sikap masyarakat adat terhadap hukum adat maka pelaksanaan tindakan dan upaya - upaya pemulihan keseimbangan dalam masyarakat tersebut dapat berjalan dengan baik.

Hal seperti ini menyatakan penerapan sanksi adat patinyawa hingga saat ini masih diterima oleh masyarakat Dayak Uud Danum, sehingga perbuatan dan tingkah laku masyarakat yang merusak tatanan kehidupan dalam masyarakat Dayak Uud Danum dapat ditekan dengan semaksimal mungkin dikenakan sanksi/hukuman/tuntutan adat kepada pelaku pelanggar hukum adat agar tidak menggangu keseimbangan kehidupan masyarakat. Untuk tercapainya suatu keputusan yang seadil - adilnya dan tidak merugikan salah satu pihak maka Kepala Adat melalui sidang adat yang dihadiri oleh masyarakat dengan bermusyawarah terlebih dahulu agar mencapai suatu kesepakatan antara pihak - pihak yang berpekara dengan mempertimbangkan segala hal - hal yang memberatkan dan meringankan pelaku.

\section{A. Penyelesaian Kasus Pembunuhan dengan menggunakan Hukum Adat Dayak Uud Danum}

\section{Menurut Ketua Adat (Tomakung)}

bahwa mereka akan melakukan tindakan apabila mendapatkan laporan ahli waris korban atau masyarakat setempat tentang adanya perbuatan yang mengakibatkan hilangya nyawa seseorang, maka temenggung adat yang menerima laporan langsung menuju tempat kejadian perkara untuk melihat keadaan korban. Penerapan sanksi adat patinyawa ini tidaklah berdasarkan pada suatu keharusan yang diatur secara tertulis, tetapi selalu didasari oleh kisah yang berkembang dalam masyarakat adat tentang upaya - upaya yang dilakukan oleh nenek moyangnya dalam memulihkan keseimbangan yang terganggu akibat perbuatan yang menghilangkan nyawa orang lain baik sengaja maupun tidak sengaja tabrakan (hototurung). Pada dasarnya manusia tidak mampu untuk meramalkan masa depannya yang akan datang, dengan demikian ketentuan hukum adat patinyawa ini bersifat 
terbuka untuk segala peristiwa atau keadaan yang berhubungan dengan perbuatan itu, sejalan perubahan jaman dan perkembangan pikiran manusia akibat arus globalisasi di segala bidang kehidupan yang semakin maju sehingga mempengaruhi kehidupan dan pola pikir manusia itu sendiri.

Selanjutnya menurut Ketua Adat yang diwawancarai oleh peneliti bahwa setelah adanya kepastian tentang laporan tersebut, maka Temenggung adat yang bersangkutan menghubungi Temenggung adat yang lebih tinggi yaitu Kepala adat (Tomakung). Setelah seluruh anggota dan ketua temenggung adat berkumpul dan melaporkan perkara tersebut kepada ahli waris pelaku, atau pihak yang berkepentingan seperti ahli waris korban. Apabila pelakunya dalam hal ini dari suku lain, maka yang dipanggil adalah Kepala Adat dari suku pelaku tersebut yang selanjutnya memberitahukan kepada si pelaku. Apabila sudah jelas, maka ahli waris pelaku bersama Kepala Adat dan Fungsionaris Adat menemui pelaku dalam tahanan pihak Kepolisian, jika pelakunya sudah tertangkap. Setelah pertemuan dengan si pelaku apabila pelaku tidak mengakui perbuatan yang dituduhkan kepadanya, maka ia harus mempunyai saksi yang bersedia bersumpah secara adat untuk membuktikan kebenaran pengakuannya, tetapi apabila pelaku tidak mempunyai saksi untuk bersumpah, dengan diakui atau tidaknya tersebut olehnya, Kepala Adat selanjutnya akan menetapkan waktu dan tempat untuk diadakan sidang adat tingkat Kecamatan yaitu (Tomakung). Kemudian disampaikan kepada ahli waris korban, sebagai pihak penuntut/ dari suku korban yang diwakilioleh fungsionaris adat sebagai pihak yang merasa terganggu kepentingan dan keseimbangan kehidupannya. Walaupun pelaku tidak mengakui perbuatannya, sidang adat tetap dilaksanakan dengan dihadiri ahli warisnya saja. Peradilan Adat ini dilakukan dirumah Adat atau dirumah Tomakung (timanggung) dan dilaksanakan pada siang hari yang dihadiri oleh para fungsionaris adat, pihak korban, pelaku/ahli warisnya, dan masyarakat adat. Bila ahli waris pelaku tidak dapat hadir pada sidang tersebut, maka sidang ditunda pada lain waktu, jika tetap ahli waris pelaku tidak hadir, maka sidang adat tetap dilaksanakan tanpa kehadiran ahli waris pelaku. Sidang Adat ini merupakan musyawarah yang pertama untuk mencapai suatu kesepakatan dalam menentukan dan menerima tuntutan yang dilakukan oleh Kepala Adat terhadap pelaku. Setelah ada kesepakatan pada musyawarah pertama ini, Kepala Adat menyampaikan kepada pihak penuntut tentang tuntutan yang dikenakan kepada pelaku. Dalam hal ini jika ahli waris korban tidak setuju, maka tuntutan 
akan dirundingkan kembali, setelah itu diperoleh persetujuan dari ahli waris korban, maka tuntutan tersebut disampaikan kepada ahli waris pihak pelaku.

Hukum adat Dayak Uud Danum di Kabupaten Sintang berlaku pada seluruh masyarakat Dayak Uud Danum pada umumnya yang mendiami Kabupaten Sintang dan khususnya pada Kecamatan Ambalau dan Serawai, karena sudah membaurnya kehidupan masyarakat adat dari berbagai suku yang sifatnya sudah heterogen. Sehingga perlu diterapkan satu aturan adat, ternyata pada hakekatnya hukum adat yang berlaku pada masyarakat Dayak Uud Danum adalah sama, maka segenap fungsionaris adat yang pernah menangani perkara adat yang timbul didalam masyarakat menyatakan hukum adat berlaku sama diantara mereka. Hukum adat ayak Uud Danum dilaksanakan lebih berat lagi, apabila yang hidup tidak mampu membayar sanksi (termasuk ahli warisnya tidak sanggup /tidak mampu untuk membayarnya), maka pelaku yang hidup tersebut harus dihukum gantung sampai mati. Tetapi setelah perkembangan peradaban dan masuknya agama, sehingga membawa masyarakat adat kearah yang lebih baik. Penerapan sanksi adat Pati Nyawa ini, tidaklah beradasarkan pada suatu keharusan yang diatur secara tertulis, tetapi selalu didasari oleh kisah yang berkembang dalam masyarakat adat tentang upaya - upaya yang dilakukan oleh nenek moyangnya dalam memulihkan keseimbangan yang terganggu akibat perbuatan menghilangkan nyawa orang lain dengan tidak sengaja.

Berdasarkan hasil wawancara dengan Ketua Adat (Tomakung) bahwa dalam Keputusan Musyawarah fungsionaris adat Kecamatan Serawai dan Ambalau telah merumuskan ketentuan adat pati nyawa yang berlaku untuk 46 Desa yang kemudian disahkan dengan keputusan Dewan Adat Dayak Kabupaten Sintang. Keputusan musyawarah Fungsionaris Adat Dayak Uud Danum sebelum direvisi yaitu sebagai berikut berkaitan dengan ketentuan hukum Adat Patinyawa :

1. Mengatur tentang penggantian tiap organ tubuh korban/ganti pati nyawa dengan benda - benda antik (pusaka), yaitu :

- Mulut diganti dengan (kolatung) gong, karena mempunyai bunyi seperti halnya mulut manusia

- Mata diganti dengan (sonavak) peluru emas, karena dapat menuju sasaran/menembus hal yang dituju, seperti mata manusia melihat sasaran dengan keinginannya.

- Telinga diganti dengan (sakuk) talam yang berkaki, karena mempunyai bentuk yang menyerupai telinga manusia.

- Rambut diganti dengan (kawat) senar kecapi, karena senar kecapi halus dan dianggap menyerupai rambut manusia.

- Perut diganti dengan ( baat ) bahan 
perak yang terlilit di perut dan

dikenakan di perut.

- Lengan diganti dengan (sonapang lantak), senapang lantak karena ukurannya menyerupai lengan manusia dan dapat diarahkan pada sasaran, serta dipatahkan pada saat diinginkan seseorang.

- Paha diganti dengan meriam kecil, karena bentuk dan ukurannya seperti paha manusia.

- Bulu diganti dengan (doih) jarum jahit, karena jarum itu halus (kecil) dan menyerupai bulu manusia.

- Sumsum diganti dengan (tomaga) tembaga bahan keras yang prosesnya dengan pembakaran akan mencair dan warnanya kekuning kuningan seperti sumsum manusia.

- Leher diganti dengan (corong ) pipa besi, karena fungsinya sama seperti leher manusia sebagai saluran masuknya air dan makanan menuju pencernaan.

- Lidah diganti dengan cangkul, karena cangkul dapat memindahkan tanah dan menampung tanah sebelum dipindahkan, seperti halnya lidah manusia yang terlebih dahulu menampung makanan untuk dirasa.

- Darah meleleh diganti dengan emas halus yang belum terbentuk, karena apabila emas itu meleleh waktu dibakar (dalam proses) maka akan meleleh seperti darah.

- Rusuk diganti (batu gorindak) batu asah yang kuat untuk menempa parang karena batu tersebut kokoh seperti halnya rusuk manusia.

- Gigi diganti dengan (kahpak) kapak, karena kapak tersebut tajam dan kuat seperti gigi manusia.

- Kepala diganti dengan (keceng) periuk, karena periuk menggambarkan ada nasi ( rejeki/ makanan) seperti halnya kepala manusia terdapat segala pikiran untuk memperoleh rejeki/nasi.

- Urat diganti dengan kawat dari tembaga, karena kawat tersebut kuat dan halus seperti urat manusia.

- Tangan diganti dengan (palu), karena kuat dipukulkan terhadap barang apa saja.

- Hidung diganti dengan (sohpot) sumpit api yang mengeluarkan hawa napas manusia sama seperti hidung manusia yang digunakan menarik dan mengeluarkan udara/ napas

- Payudara diganti dengan mangkok karena menyrupai susu manusia.

- Biji kemaluan pria diganti dengan (umat bulat koik) besi bulat ukuran kecil.

- Kemaluan pria diganti dengan (lading) keris

- Pinggang diganti dengan (aluk umat) tiang bulat penumbuk beras dari besi yang berbentuk pinggang manusia.

- Kemaluan wanita diganti dengan caping kecil yang terbuat dari tembaga dan berbentuk segi tiga, karena bentuk dan ukuran yang menyerupai kemaluan wanita.

- Kuku diganti dengan (sambon) perak kecil yang pipih, yang bentuknya menyerupai kuku manusia dan kuat serta dapat membuat perhiasan seperti kuku manusia.

- Jari - jari diganti dengan (tisim bulou) cincin emas ( 10 gram ) khusus untuk jari manis, sedangkan untuk jari keseluruhannya (ragak) yang berfungsi untuk menampung barang makanan seperti halnya jari - jari manusia yang berfungsi untuk memegang barang.

2. Mengatur tentang ketentuan dasar 
bagi upaya - upaya pemulihan kesimbangan, yaitu sebagai berikut :

- Beras (paroi) beras untuk masak nasi 70gantang

- Beras (pulut) beras ketan 70gantang

- Talam (sakuk) antik 7buah

- Mangkok antik 7buah

- Piring (pinjan antic) 7buah

- Tombak 7buah

- Parang (iso) 7buah

- Temapt sirih dari tembaga (kosalah sipak) 7 buah

- Gong (kolatung) besar 7buah

- Gong (kolatung) kecil 7buah

- Tempayan (potoran) besar 7buah

- Mandau (ahpang antic) 7buah

- Babi (urak) 7ekor

- Anjing (asuk) 7ekor

- Ayam putih dan hitam (manuk mitom putik) 7ekor

- Tuak (boram) 7tempayan

- Garam Makan (tonyuk) 7bungkus

- Micin 7bungkus

- Gula merah 77kg

- Gula pasir 7kg

- Kopi $7 \mathrm{~kg}^{14}$

Ketentuan Hukum Adat Pati Nyawa yang telah dirumuskan itu seperti dikatakan diatas mencakup 3 (tiga) hal yaitu :

A Mengatur tentang Adat Pati Nyawa sebesar 30 Ulun jika didiganti kan ke Rupiah sebesar Rp.30.000.000,-(tiga puluh juta rupiah)

B. Adat Nyolat (prosesi upacara kematian tahap pertama)

1. Babi sambut mayat 1 ekor berat 40 Kg. a Rp.30.000 = Rp. 1.440 .000

2. Babi untuk nidur mayat malam pertama 1 ekor $30 \mathrm{Kg}$. a x Rp.40.000 = Rp.1.200.000

3. Babi untuk nidur mayat malam kedua 1 ekor $38 \mathrm{Kg}$.

14 Keputusan musyawarah adat bersama para petugas adat Dayak Uud Danum tentang Rekapitulasi Adat dayak Uud Danum Kabupaten Sintang. a x Rp.40.000 = Rp.1.520.000

4. Babi untuk gali kubur 1 ekor $25 \mathrm{Kg}$. a x Rp.40.000 = Rp.1.000.000

5. Babi untuk ngubur mayat 1 ekor 28 $\mathrm{Kg}$.

a x Rp.40.000 =Rp.1.120.000

6. Babi untuk nginjan daun 1 ekor 35

$\mathrm{Kg}$.

a x Rp.40.000 = Rp. 1.400 .000

7. Babi untuk nyolat sopolahkik aluk 3 ekor

$1.72 \mathrm{Kg}$.

a x Rp. $40.000=$ Rp. 2.880 .000

$2.36 \mathrm{Kg}$.

a $\mathrm{X}$ Rp. $40.000=\mathrm{Rp} .1 .440 .000$

$3.29 \mathrm{Kg}$.

a x Rp.40.000 = Rp.1.160.000

8. Ayam $14 \mathrm{Kg}$.

a x Rp.50.000 = Rp.700.000

9. Beras $100 \mathrm{Kg}$. a x Rp.10.000 = Rp.1.000.000

10. Arak 2 ( dua ) ken. a x Rp.500.000 = Rp.1.000.000

11. Bir Putih 2 (dua ) dus. a x Rp. $250.000=\mathrm{Rp} .500 .000$

12. Gula $30 \mathrm{Kg}$. a x Rp. $14.000=R p .420 .000$

13. Kopi 1 ( satu ) dus $=$ Rp. 420.000

14. Bawang Putih + Merah $4 \mathrm{Kg}$. a x Rp. $15.000=$ Rp.60.000

15. Minyak Goreng $5 \mathrm{Kg}$. a x Rp. $20.000=$ Rp. 100.000

16. Kecap Manis 5 ( lima ) botol. a x Rp.20.000 = Rp. 100.000

17. Sabun Cuci 10 ( sepuluh ) batang. a x Rp.7.000 = Rp.70.000

18. Indomie 6 ( enam ) dus. a x Rp.52.000 = Rp.312.000

19. Rokok Surya 6 ( enam ) slop. a x Rp. $100.000=$ Rp.600.000

20. Rokok Longlat 1 ( satu ) bantal $=\mathrm{Rp}$. 115.000

21. Garam + Micin = Rp. 50.000

22. Solar 40 liter $. \mathrm{a} \times \mathrm{Rp} .80 .000=$ Rp. 320.000

23. Kain panjang 16 lembar. 
a x Rp.35.000 = Rp.560.000

24. Saprai ( 1 ) set $=$ Rp. 100.000

25. Tikar 1 ( satu ) buah $=$ Rp. 80.000

26. Tenda (satu) buah $4 \times 6 \mathrm{~m}=\mathrm{Rp}$. 400.000

27. Paku 2 ( dua ) Kg. a x Rp. $25.000=$ Rp. 50.000

28. Tembakau lipat 1 (satu ) kotak = Rp. 220.000

29. Tuak 4 ( empat ) ember. a x Rp. $220.000=$ Rp. 880.000

30. Bola Lampu 10 ( sepuluh ) biji .a x Rp. $4.000=$ Rp. 40.000

31. Lonang 1 (satu ) dus = Rp. 490.000

32. Semen 4 (empat) sak. a $x$ Rp. $125.000=$ Rp. 500.000

33. Biaya angkat mayat $=$ Rp. 800.000 Jumlah $=$ Rp.22.767.000

C. Adat Dalok

1. Babi untuk notuot katung 1 ( satu ) ekor $54 \mathrm{Kg}$. a x Rp.40.000 = Rp.2.160.000

2. Babi untuk nyemen kuburan 1 (satu ) ekor $60 \mathrm{Kg}$. a x Rp.40.000 = Rp.2.400.000

3. Babi untuk motong kayu,bikin pagar, nohkak ucak 1 ekor $38 \mathrm{Kg}$.a x Rp. $40.000=$ Rp. 1.520 .000

4. Babiuntuksakinbatoi1(satu)ekor30Kg. a x Rp.40.000 = Rp.1.120.000

5. Babi untuk bikin temadu (patung Sopunduk) selama 3 (tiga hari 3 (ekor) Hari pertama 1 (satu ) ekor $50 \mathrm{Kg}$ .a $\mathrm{x}$ Rp.40.000 = Rp.2.000.000 Hari kedua 1 ( satu ) ekor $40 \mathrm{Kg}$ .a $\mathrm{x}$ Rp.Rp.40.000 = Rp.1.600.000 Hari ketiga 1 (satu ) ekor $50 \mathrm{Kg}$.a x Rp.40.000 = Rp.2.000.000

6. Babi 1 ( satu ekor) $112 \mathrm{Kg}$ hari terakhir pelaksanaan Dalok .a $\mathrm{x}$ Rp.40.000 = Rp.4.480.000

7. Sapi Bagong 1 ( satu ) ekor hari terakhir pelaksanaan Dalok = Rp.15.000.000

8. Ayam $25 \mathrm{Kg}$. a x Rp. $50.000=$ Rp.1.250.000
9. Upah bikin Sepanduk $=$ Rp. 1.600 .000

10. Beras $200 \quad \mathrm{Kg}$. a x Rp.10.000 = Rp.2.000.000

11. Semen 6 ( enam ) sak. a x Rp. $125.000=$ Rp.750.000

12. Porselin 8 ( delapan ) kotak. a x Rp. $150.000=$ Rp. 1.200 .000

13. Arak 8 Ken. a x Rp.500.000 = Rp.4.000.000

14. Manic - manic 2 (dua) buah. a x Rp. $50.000=$ Rp. 100.000

15. Minyak solar 100 ( seratus ) Liter. a x Rp. $8.000=$ Rp. 800.000

16. Tembakau tepek 1 kotak $=\mathrm{Rp}$. 220.000

17. Garam $5 \quad$ Bungkus. a x Rp. $2.000=$ Rp. $\quad 100.000$

18. Micin 2 ( dua ) Kg. a x Rp. $30.000=$ Rp. 60.000

19. Bawang Merah, Putih, Ketumbar dan lain - lain bumbu masak $=$ Rp.500.000

20. Kopi 5 ( lima $) \mathrm{Kg}$. a x Rp.40.000 = Rp.200.000

21. Gula 50 ( lima puluh ) Kg. a x Rp. $14.000=$ Rp.700.000

22. Biaya Kotang Tulang $=$ Rp. 800.000

23. Tenda Balai Palik 2 ( dua ) buah. a x Rp. $150.000=R p .300 .000$

24. Kain 10 lembar. a x Rp.35.000 = Rp.350.000

25. Upah tukang Kuburan = Rp.1.000.000 Jumlah=Rp.48.210.000

Perincian Biaya Adat pati Nyawa + Nyolat + Dalok $=$ Rp.100.977.000 ${ }^{15}$.

15 Keputusan Dewan Adat Dayak Terhadap Penyelesaian Adat Kematian Dayak Uud Danum Di Kabupaten Sintang, 1987. 


\section{B. Faktor - Faktor penyebab masyarakat Adat menyelesaikan kasus pembunuhan dengan menggunakan Hukum Adat Dayak Uud Danum.}

Menurut Keluarga Korban bahwa Kehidupan masyarakat Dayak Uud Danum yang selayaknya di kuasai oleh alam pikiran religiomagis, diantaranya dapat dilihat pada saat menyelesaikan kasus pembunuhan dengan menggunakan hukum adat daripada hukum positif. Suatu sifat yang bijaksana untuk menentukan hukum mana yang akan dipilih terkait kasus yang dihadapi untuk menyelesaikan perkara dan mengembalikan keseimbangan yang sebelumnya terbina harmonis bersama dengan alam sekitarnya. Penyebab masyarakat memilih hukum Adat Dayak Uud Danum untuk menyelesaikan kasus dimana terdapat dua sumber hukum yang perlu dipilih oleh pihak - pihak yang berperkara, adapun faktor - faktor yang menjadi penyebab masyarakat Adat Dayak Uud Danum memilih Hukum Adatnya untuk menyelesaikan kasus Pembunuhan sebagai berikut :

1. Masyarakat setempat masih mempercayai keseimbangan antara alam hidup dan alam perlu dijaga yang berarti setiap pelanggaran adat harus diselesaikan baik secara Konkrit (nyata) dan fiktif (belaka) yang tidak kelihatan.

2. Apabila tidak diselesaikan dengan hukum adat setempat maka akan terjadi bencana alam menimpa kampung si pelaku dan atau korban.

3. Untuk menjaga, mempertahankan, dan menghormati hukum yang berlaku di daerah setempat sehingga tidak terkikis oleh perubahan zaman dan teknologi yang semakin menghimpit.

4. Untuk menyadarkan kepada siapapun yang hendak berkunjung ke daerah tersebut mengetahui adat - istiadat setempat bukan hanya datang secara illegal tanpa permisi kepada tuan rumah.

5. Berpikir bahwa dengan penyelesaian secara hukum adat setempat mengurangi penekanan dari pihak lain baik secara materil maupun imateril seperti pendanaan dan bantuan berbagai pihak.

6. Mengurangi biaya yang dikeluarkan dari berbagai pihak yang berperkara, dimana mayoritas penduduk sebagai petani yang berpendapatan menengah kebawah.

7. Memperpendek tahapan proses perkara yang menghabiskan hanya berapa hari dengan berbagai agenda sidang Dewan Adat setempat.

8. Menghormati dan rasa belasungkawa dengan pembayaran uang patinyawa kepada keluarga korban yang ditinggalkan .

9. Ketaatan masayarakat adat yang tinggi terhadap Hukum adatnya dengan artian bahwa siapa lagi yang mentaati hukumnya selain mereka yang mengakui dirinya suku Dayak Uud Danum, sudah barang asing orang luar mentaati hukumnya.

10. Kedekatan dengan alam sekitar masih sangat tinggi karena kebanyakan penduduk suku Dayak Uud Danum ini masih bekerja sebagai petani yang setiap hari keluar masuk hutan, sehingga keseimbangan kosmis dengan keseimbangan kehidupan di masyarakat sangat bergantung 
terhadap perilaku manusianya.

\section{Simpulan}

Berdasarkan hasil penelitian maka

dapat disimpulkan bahwa :

1. Penerapan sanksi adat pati nyawapada dasarnya tidak terlepas dari pengaruh hukum positif dalam hal penyidikan, penangkapan, penahanan, pemenuhan sanksi adat, dan pembuktian atas kesalahan dari pelaku yang dituntut terhadap sanksi adat tidak dipenuhi oleh pihak pelaku.

2. Penerapan sanksi adat pati nyawa terhadap pelaku pembunuhan dipercayai oleh masyarakat adat Dayak Uud Danum dapat mengembalikan keseimbangan kehidupan, dunia gaib yang dinodai oleh pelaku.

3. Pembayaran denda adat sebagai sanksi adat pati nyawa atas perbuatan menghilangkan nyawa orang lain (hototurung) yang masih diterapkan guna menyelesaiakan perkara sejalan dengan keadilan dan kepatuhan hukum masyarakat adat. saran - saran Penelitian sebagai berikut :

a Diharapkan kepada para fungsionaris adat agar sekiranya dalam menerpakan sanksi adat yang diselesaikan dengan cara cicilan dibuatkan sebuah kwitansi atas bukti dari pembayaran sanksi adat pati nyawa tersebut, sebagai bukti otentik aats pembayaran itu dapat memperlancar dan menghindari masalah yang timbul dikemudian hari sehubungan dengan pelunasan sanksi adat berikutnya.

b. Diharapkan semua masyarakat Dayak Uud Danum tidak berpikir dangkal dalam menyimpulkan prosesi penyelesaian sanksi adat pati nyawa ini dengan pikiran bahwa nyawa bisa diganti dengan selembar uang, padahal nyawa seseorang tidak ada sama sekali seseorang masnusia di dunia ini yang mampu menggantikan nyawa orang lain, dan sanksi adat pati nyawa tersebut hanya sebagai santunan dan ucapan bela sungkawa dari pihak pelaku kepada pihak korban agar perbuatan tersebut dapat dimaafkan baik oleh keluarga korban,masyarakat, dan mengembalikan keseimbangan kehidupan serta keseimbangan kosmis yang terganggu akibat perbuatan si pelaku.

c. Diharapkan kepada Fungsionari dan Masayarakat Adat mampu mempertahankan Adat Pati Nyawa ini sampai waktuyang takj terhingga, karena manusia yang tidak memiliki suku bangsa berarti dia tidak memiliki identitas diri.

\section{DAFTAR PUSTAKA}

Hilman Hadikusmah, 1984. Hukum Pidana Adat,Alumni Bandung,

Imam Sudayat, . 1989. Hukum Adat . Liberty , Yogyakarta,

Keputusan Dewan Adat Dayak Terhadap Penyelesaian Adat Kematian Dayak Uud Danum Di Kabupaten Sintang Tahun 2000

Moeljatno,. 2002. Asas - Asas Hukum Pidana,Rineka Cipta,Cetakan ke-7 Jakarta,

P.A.FLamintang, 1984. Kitab Undang Undang Hukum Acara Pidana dengasn pembahasan secar Yuridis menurut Yurisprudensi dan Ilmu Pengetahuan Hukum Pidana, Sinar Baru, Bandung,

Rmikel Commans, 1987. Manusia Dayak , Dahulu, Sekarang, Masa Depan, Gramedia, Jakarta,

R.Soepomo, 1977. Pengantar dan Asas - Asas Hukum Adat, Prdarnya, Jakarta . 
Utrecht. 1996. "Pengantar Tata Hukum Indonesia " Karangan, penerbit Unioversiats Jakarta.

\section{Peraturan Perundangan - undangan :}

Hukum Adat Masyarakat Suku Dayak Uud Danum Kecamatan Serawai Ambalau,hasil keputusan Musdat Tahun 2001, Serawai

Undang - Undang Nomor 1 Tahun 1946 tentang Peraturan Hukum Pidana Indonesia.

Undang - Undang Nomor 29 Tahun 1999 tentang Perubahann Kitab Undang Undang Hukum Pidana (KUHP) yang berkaitan dengan kejahatan terhadap Keamanan Negara. 